\title{
Mechanisms of ATP to cAMP Conversion Catalyzed by the Mammalian Adenylyl Cyclase: A Role of Magnesium Coordination Shells and Proton Wires
}

\author{
Bella Grigorenko, ${ }^{1,2}$ Igor Polyakov, ${ }^{1,2}$ Alexander Nemukhin ${ }^{1,2, *}$
}

1 Chemistry Department, M.V. Lomonosov Moscow State University, 1-3 Leninskiye Gory, Moscow 119991, Russia

2 N.M. Emanuel Institute of Biochemical Physics, Russian Academy of Sciences, 4 Kosygin Street, Moscow 119334, Russia

*Corresponding author: Prof. Alexander Nemukhin

Chemistry Department, M.V. Lomonosov Moscow State University, 1-3 Leninskiye Gory, Moscow 119991, Russia

E-mail: anemukhin@yahoo.com; anem@1cc.chem.msu.ru 


\begin{abstract}
We report a mechanism of adenosine triphosphate (ATP) to cyclic adenosine monophosphate (cAMP) conversion by the mammalian type $\mathrm{V}$ adenylyl cyclase revealed in molecular dynamics (MD) and quantum mechanics/molecular mechanics (QM/MM) simulations. We characterize a set of computationally derived enzyme-substrate (ES) structures showing an important role of coordination shells of magnesium ions in the solvent accessible active site. Several stable six-fold coordination shells of $\mathrm{Mg}_{\mathrm{A}}{ }^{2+}$ are observed in MD simulations of ES complexes. In the lowest energy ES conformation, the coordination shell of $\mathrm{Mg}_{\mathrm{A}}{ }^{2+}$ does not include the $\mathrm{O}_{\delta 1}$ atom of the conserved Asp440 residue. Starting from this conformation, a one-step reaction mechanism is characterized which includes proton transfer from the ribose $\mathrm{O}^{3} \mathrm{H}^{3}$ group in ATP to Asp440 via a shuttling water molecule and $\mathrm{P}^{\mathrm{A}}-\mathrm{O}^{3 \mathrm{~A}}$ bond cleavage and $\mathrm{O}^{3}-\mathrm{P}^{\mathrm{A}}$ bond formation. The energy profile of this route is consistent with the observed reaction kinetics. In a higher energy ES conformation, $\mathrm{Mg}_{\mathrm{A}}{ }^{2+}$ is bound to the $\mathrm{O}_{\delta 1}($ Asp440) atom as suggested in the relevant crystal structure of the protein with a substrate analog. The computed energy profile initiated by this ES is characterized by higher energy expenses to complete the reaction. Consistently with experimental data, we show that the Asp440Ala mutant of the enzyme should exhibit a reduced but retained activity. All considered reaction pathways include proton wires from the $\mathrm{O}^{3^{\prime}} \mathrm{H}^{3^{\prime}}$ group via shuttling water molecules.
\end{abstract}




\section{Introduction}

Studies of chemical mechanisms in adenylyl cyclases (AC) are justified by an importance of the enzyme-catalyzed conversion of adenosine triphosphate (ATP) to cyclic adenosine monophosphate (cAMP). ${ }^{1}$ It is enough to mention a role of adenylyl cyclases in human health and diseases due to key regulatory functions of these enzymes in essentially all cells. ${ }^{2}$ Numerous biochemical, biological and biomedical papers discuss various aspects of structure and function of ACs, some of them tentatively formulate catalytic mechanisms of the reaction ATP $\rightarrow$ cAMP inside enzyme active

sites, and only three papers ${ }^{3-5}$ report somewhat inconsistent results of quantum-based simulations of this reaction in proteins.

Fig. 1 illustrates schematically the ATP-containing pocket in the mammalian type V adenylyl cyclase showing several critical residues (numbered according to the crystal structure PDB ID $1 \mathrm{CJK}^{6}$ ) and two metal ions. We also show the atom names in the ATP molecule used in this paper as well as expected transformations with ATP eventually leading to the reaction products, cAMP and pyrophosphate (PPi). Here we consider the magnesium ions in the A and B metal sites (proteins with the manganese ions are also studied in experimental works); both of them are trapped by coordination bonds with oxygen atoms from their coordination shells. The key issue for the ATP $\rightarrow$ cAMP reaction is a proton transfer route from the ribose group $\mathrm{O}^{3} \mathrm{H}^{3}$, which facilitates a nucleophilic attack of $\mathrm{O}^{3^{\prime}}$ on the $\mathrm{P}^{\mathrm{A}}$ atom. 


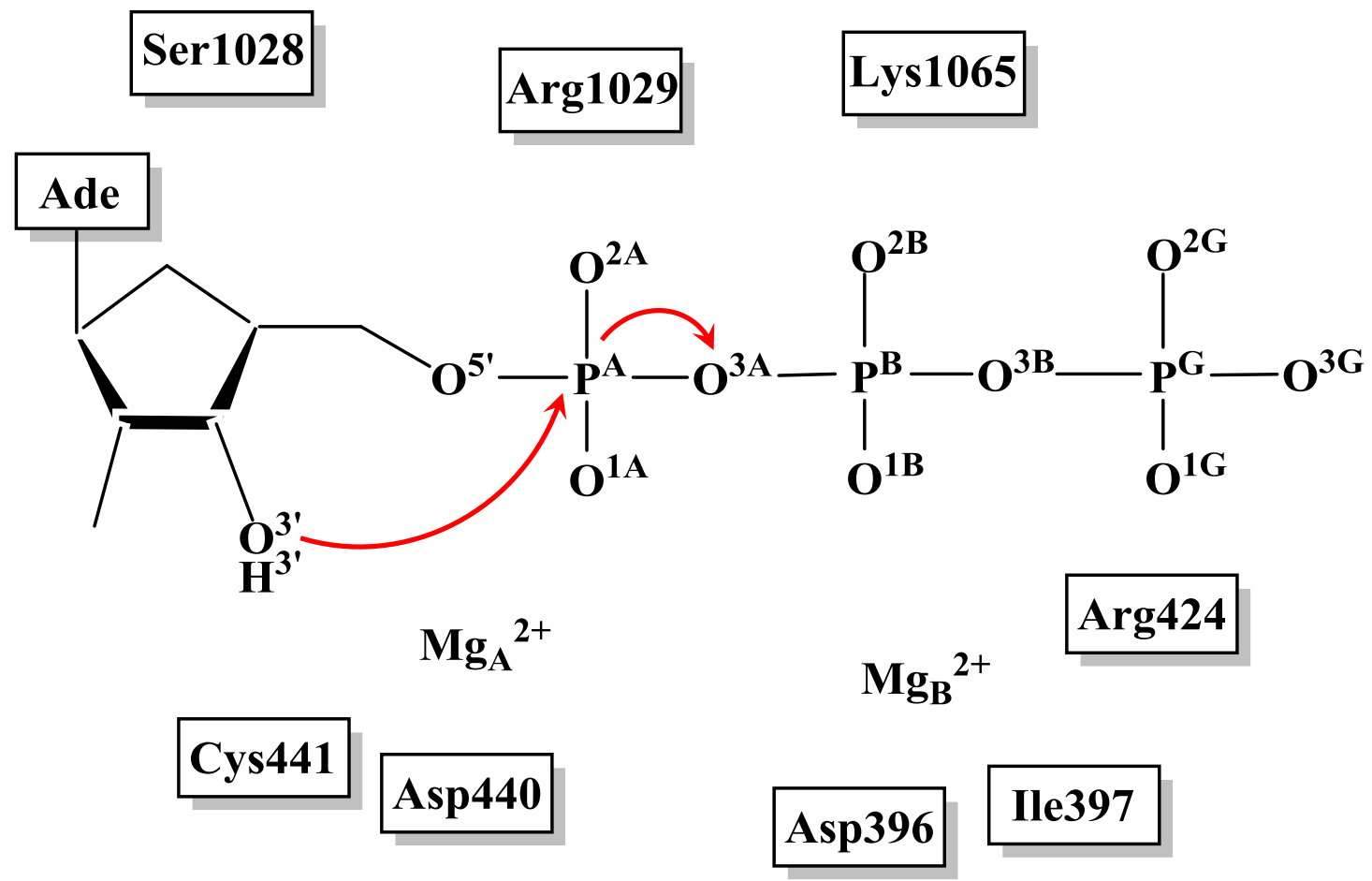

Figure 1. The ATP molecule inside the substrate-containing pocket in the mammalian type $\mathrm{V}$ adenylyl cyclase, ${ }^{6}$ showing expected transformations in the reaction ATP $\rightarrow$ cAMP.

The ATP $\rightarrow$ cAMP reaction catalyzed by the AC domain of the anthrax edema factor toxin was modeled by Mones et al. ${ }^{3}$ in 2013 using the empirical valence bond version of the quantum mechanics/molecular mechanics (QM/MM) method. This approach ${ }^{7}$ allows one to predict a reaction energy profile in enzymes with potentials calibrated with respect to the reference profile in solution. Mones et al. ${ }^{3}$ considered two possible mechanisms of the enzyme-catalyzed reaction: first, a mechanism assuming $\mathrm{H}^{3 \prime}$ proton transfer to a nearby histidine residue; second, a reaction pathway that involved $\mathrm{H}^{3}$ proton transfer to the oxygen atom $\mathrm{O}_{\mathrm{w}}$ of an unspecified water molecule in the bulk. In both cases, subsequent steps of formation of an unstable intermediate with the pentacoordinated phosphorus $\mathrm{P}^{\mathrm{A}}$ and its decomposition into cAMP and pyrophosphate (PPi) were modeled. Following calculation results, the first mechanism was rejected due to unrealistically large 
activation barriers of almost $30 \mathrm{kcal} / \mathrm{mol}$. Activation energy barriers of $12 \div 14 \mathrm{kcal} / \mathrm{mol}$ consistent with kinetic measurements were estimated for the second option.

In 2016, Jara and Martínez ${ }^{5}$ simulated the ATP $\rightarrow$ cAMP reaction, first, also in the AC domain of the anthrax edema factor toxin; second, in the mammalian AC. For the case of mammalian AC, the authors relied on the crystal structure PDB ID $1 \mathrm{CJK}{ }^{6}$ Experimentally, the protein was crystallized with an ATP analog, adenosine 5'-( $\alpha$-thio)-triphosphate (ATP $\alpha$ S-Rp), one magnesium ion $\mathrm{Mg}_{\mathrm{A}}{ }^{2+}$ and one manganese atom $\mathrm{Mn}_{\mathrm{B}}{ }^{2+} .6$ The authors of the computational paper 5 created model systems restoring proteins with ATP and two magnesium ions in the active sites, carried out molecular dynamics (MD) simulations with the classical and QM/MM potentials. The semi-empirical density functional tight-binding method with the self-consistent charge approach (SCC-DFTB) ${ }^{8,9}$ was applied in QM/MM simulations. The obtained energy profiles were corrected in single-point DFT calculations using the B3LYP and M06 functionals. As in Ref 3, a histidine residue was considered as a general base in the $\mathrm{O}^{3} \mathrm{H}^{3}$ deprotonation in the edema factor toxin, while a water molecule was assumed a catalytic base in the mammalian AC. The computed energy profiles are consistent with a one-step mechanism in both enzymes with a penta-coordinated $\mathrm{P}^{\mathrm{A}}$ in the transition states. The activation barrier about $13 \mathrm{kcal} / \mathrm{mol}$ was obtained for the AC domain of the anthrax edema factor toxin, while barriers of $29 \mathrm{kcal} / \mathrm{mol}$ for the forward reaction and $37 \mathrm{kcal} / \mathrm{mol}$ for the backward reaction were estimated for the mammalian AC.

A year earlier (2015) Hahn et al. ${ }^{4}$ described computationally the reaction mechanism of ATP to cAMP conversion in the same mammalian AC domain as in Ref 5. The authors started from the same set of atomic coordinates from the crystal structure PDB ID 1CJK, ${ }^{6}$ prepared a full-atom model system with the restored ATP molecule from the ATP $\alpha \mathrm{S}-\mathrm{Rp}$ analog and two magnesium ions, selected a molecular cluster of about 200 atoms mimicking a fragment of the enzyme-substrate complex, fixed coordinates of the $\mathrm{C}_{\alpha}$ atoms of the key residues at their positions in the crystal and 
employed quantum chemical calculations to scan energy surfaces for several assumed reaction pathways. The M06 functional in the Kohn-Sham DFT approach and 6-31G* basis were used for the explicit molecular cluster, while the polarizable continuum model was applied to simulate an effect from the rest of the protein and solvent shells. The authors reported the "most probable" reaction mechanism, which included 5 elementary steps grouped into the proton transfer, conformational change, and phosphoryl transfer steps. Unlike studies described in Ref 5, the proton transfer route was clearly specified, namely, a proton wire from the $\mathrm{O}^{3^{\prime}} \mathrm{H}^{3^{\prime}}$ ribose group via a shuttling water molecule $\mathrm{W}_{\mathrm{s}}$ to the non-bridging oxygen of the $\gamma$-phosphate of ATP was considered as a preferable pathway. The free energy profile was estimated by correcting energies at stationary points on the potential energy surface by entropy contributions. The computed activation barrier for the ratedetermining phosphoryl transfer step was $17.9 \mathrm{kcal} / \mathrm{mol}$.

Thus, two quantum-based studies ${ }^{4,5}$ of the ATP $\rightarrow$ cAMP reaction mechanism in the same mammalian AC and initiated by the same set of initial coordinated prompted by the crystal structure PDB ID 1CJK resulted in notably different conclusions. Hahn et al. ${ }^{4}$ describe a multi-step mechanism with reasonable energy barriers and point out the destination point of the proton transfer route at the $\gamma$-phosphate group. Jara and Martínez ${ }^{5}$ describe a single-step mechanism with strongly overestimated energy barriers and without specification of the proton transfer pathway. Both studies 4,5 agree that this reaction refers to the mechanism with a penta-coordinated structure of the transitions state (TS5 in Ref 4, TS in Ref 5). On the contrary, simulations in Ref 3 for a related enzyme predicted a penta-coordinated structure as an unstable reaction intermediate.

From the experimental side, the rate constants of the reversible reaction E-ATP $\leftrightarrow$ E-cAMP-PPi in the same enzyme (mammalian AC) that was considered in simulations ${ }^{4,5}$ were fitted in the kinetic scheme described in Ref 10. The reported values for the forward and backward reactions, 
$59 \mathrm{~s}^{-1}$ and $2.6 \mathrm{~s}^{-1}$, correspond to the energy barriers of $15.3 \mathrm{kcal} / \mathrm{mol}$ and $17 \mathrm{kcal} / \mathrm{mol}$, respectively, if the transitions state theory is applied.

Tentative reaction mechanisms are also discussed in experimental studies. Liu et al. ${ }^{11}$ notice that a conservative Asp residue stands in an optimal position to the ribose $3^{\prime}$ hydroxyl to serve as a catalytic base. However, a later work ${ }^{6}$ showed that replacement of this residue (Asp440 in canine type $\mathrm{V}$ adenylyl cyclase) by Ala or Asn reduced activity of the enzyme with respect to ATP to cAMP conversion approximately 2000 times (with magnesium ions). The authors conclude that Asp440 is unlikely to be a general base because its replacement does not abrogate enzyme activity.

Given the importance of the ATP $\rightarrow$ cAMP reaction in mammalian ACs and controversy in conclusions of previous simulations, we perform a new set of calculations of reaction steps using the QM/MM theory. Our novel results reveal an important role of magnesium coordination shells and of proton wires via shuttling water molecules as well as the significance of the critical residue Asp440 in validating the reaction mechanism.

\section{Models and Methods}

The crystal structure PDB ID $1 \mathrm{CJK}^{6}$ (A, B chains) of type V adenylyl cyclase complexed with the ATP analog ATP $\alpha$ S-Rp and metal ions $\mathrm{Mg}_{\mathrm{A}}{ }^{2+}$ and $\mathrm{Mn}_{\mathrm{B}}{ }^{2+}$ was used as a source of initial coordinates of heavy atoms. To construct a model system for the enzyme-substrate (ES) complex we replaced the sulfur atom in the ATP analog by oxygen and the manganese ion by $\mathrm{Mg}_{\mathrm{B}}{ }^{2+}$. This simulation step is similar to that applied in previous theoretical studies. ${ }^{4,5}$ Ref 4 reports the computationally optimized structures of selected stationary points on the reaction route; therefore we compare below the results of our simulations with those from Ref 4 for the ES complex.

Hydrogen atoms were added using MM-based tools; the side chains of Arg and Lys were assumed positively charged, side chains of Glu and Asp negatively charged. The model system was completely surrounded by shells of water molecules (see Fig. S1 in Supporting Information). 
Classical molecular dynamics simulations using NAMD ${ }^{12}$ with the CHARMM force field parameters $^{13}$ (corrected for the ATP molecule as suggested in Ref 14) were performed before carrying out QM/MM calculations.

MD simulations revealed that several water molecules are inside the cavity occupied by the substrate, nearby residues and metal ions. Fig. 2 illustrates the issue showing the entrance to the cavity from the bulk solvent. As we see below, presence of water molecules in the active site is essential for understanding the reaction mechanism.

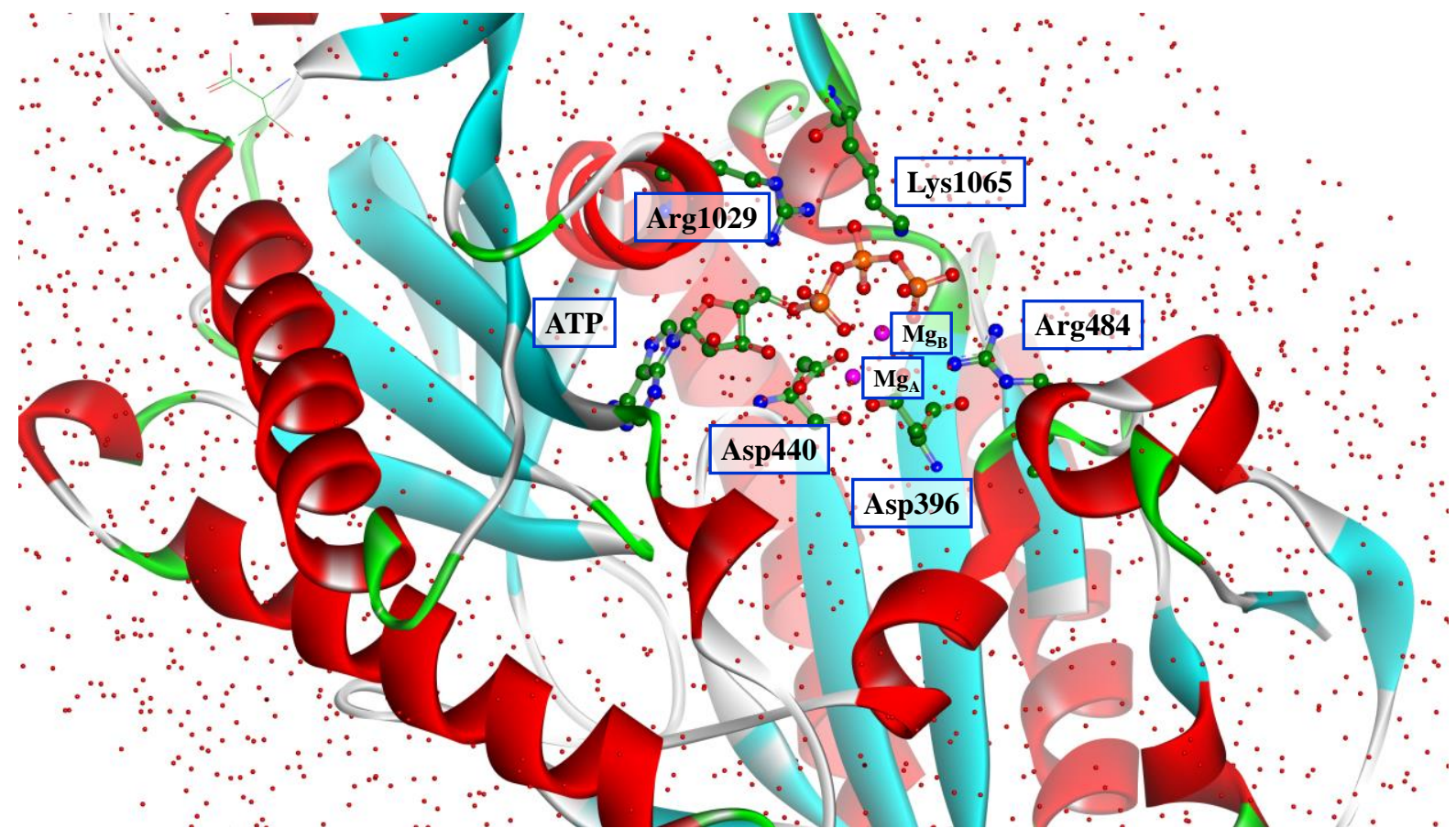

Figure 2. Fragment of the model system showing the solvent accessible active site overcrowded with the charged molecular groups. Hydrogen atoms are not shown. Here and in all figures below, carbon atoms are drawn in green, oxygen in red, nitrogen in blue, phosphorus in orange, magnesium in magenta. Red dots represent water molecules.

The molecular groups, which were included to the QM subsystem (together with the nearby 12 water molecules) upon simulation of the reaction pathway using the QM/MM method, ${ }^{15-18}$ are shown schematically in Fig. 1. The QM subsystem showing all-atom molecular groups is drawn in Fig. S2 in Supporting Information. The rest of the system was included to the MM-part. 
Calculations of energies and energy gradients in QM were carried out using the Kohn-Sham DFT approach with the PBE0 functional ${ }^{19}$ and 6-31G* basis set. The empirical dispersion correction terms D-3 ${ }^{20}$ were added. The AMBER force field ${ }^{21}$ was used in the MM subsystem. The NWChem software package ${ }^{22}$ was applied to scan QM/MM potential energy surface along the assumed reaction coordinates.

Unconstrained QM/MM minimization when starting from different MD frames allowed us to locate several minimum energy points describing the enzyme-substrate complex. We shall discuss the corresponding structures in Results. The low energy structures of ES were considered as starting points on the reaction route. The relaxed scans on the energy surface along appropriate coordinates allowed us to locate vicinities of saddles point separating local minima or the points of reaction intermediates as discussed in Results. The corresponding structures were located in series of constrained and unconstrained QM/MM minimizations. Multiple passages in the forward and backward directions between the obtained points allowed us to verify that the true structures were located in every case. We did not intend to construct free energy profiles for a direct comparison with the experimental kinetic data. Instead, our goal was to compare mostly qualitative features of reaction mechanisms initiated from various conformations of ES.

\section{Results and Discussion}

\section{Computationally derived structures of the ES complex}

Several minimum energy points on the QM/MM potential surface were located for the model system with the ATP molecule in the active site (see Fig. 2 and Fig. S1). These points refer to different structures of the ES complex, in which different conformations of the ribose fragment of ATP and different structures of the $\mathrm{Mg}_{\mathrm{A}}{ }^{2+}$ coordination shells are noted. Four lowest energy structures denoted here $\mathrm{ES}_{\mathrm{A}}, \mathrm{ES}_{\mathrm{B}}, \mathrm{ES}_{\mathrm{C}}, \mathrm{ES}_{\mathrm{D}}$ are illustrated in Fig. 3; their selected properties are collected in Table 1. Coordination shells of $\mathrm{Mg}_{\mathrm{B}}{ }^{2+}$ are similar in all ES structures. Both magnesium 
ions form six-fold coordination shells in every structure. In Fig. 3, selected magnesium coordination bonds are shown in dashed lines, other bonds connect the metal ions to water molecules in the solvent accessible cavity of the active site.

We pay attention to the following structural elements in these candidates for a productive ES

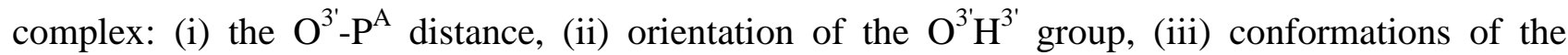
Asp396 and Asp440 side chains, (iv) coordination bonds of $\mathrm{O}_{\delta}$ atoms of Asp440 with the magnesium ions, (v) occurrence of a potentially shuttling water molecule near the $\mathrm{O}^{3^{\prime}} \mathrm{H}^{3^{\prime}}$ group. The latter issue, i.e. the presence of a water molecule near $\mathrm{O}^{3} \mathrm{H}^{3^{\prime}}$ is essential. All three previous computational papers ${ }^{3-5}$ consider a scenario with proton transfer from $\mathrm{O}^{3} \mathrm{H}^{3^{\prime}}$ to a water molecule. The latter serves either as a final proton acceptor ${ }^{3,5}$ or as a proton shuttle in an appropriate proton wire route. ${ }^{4}$

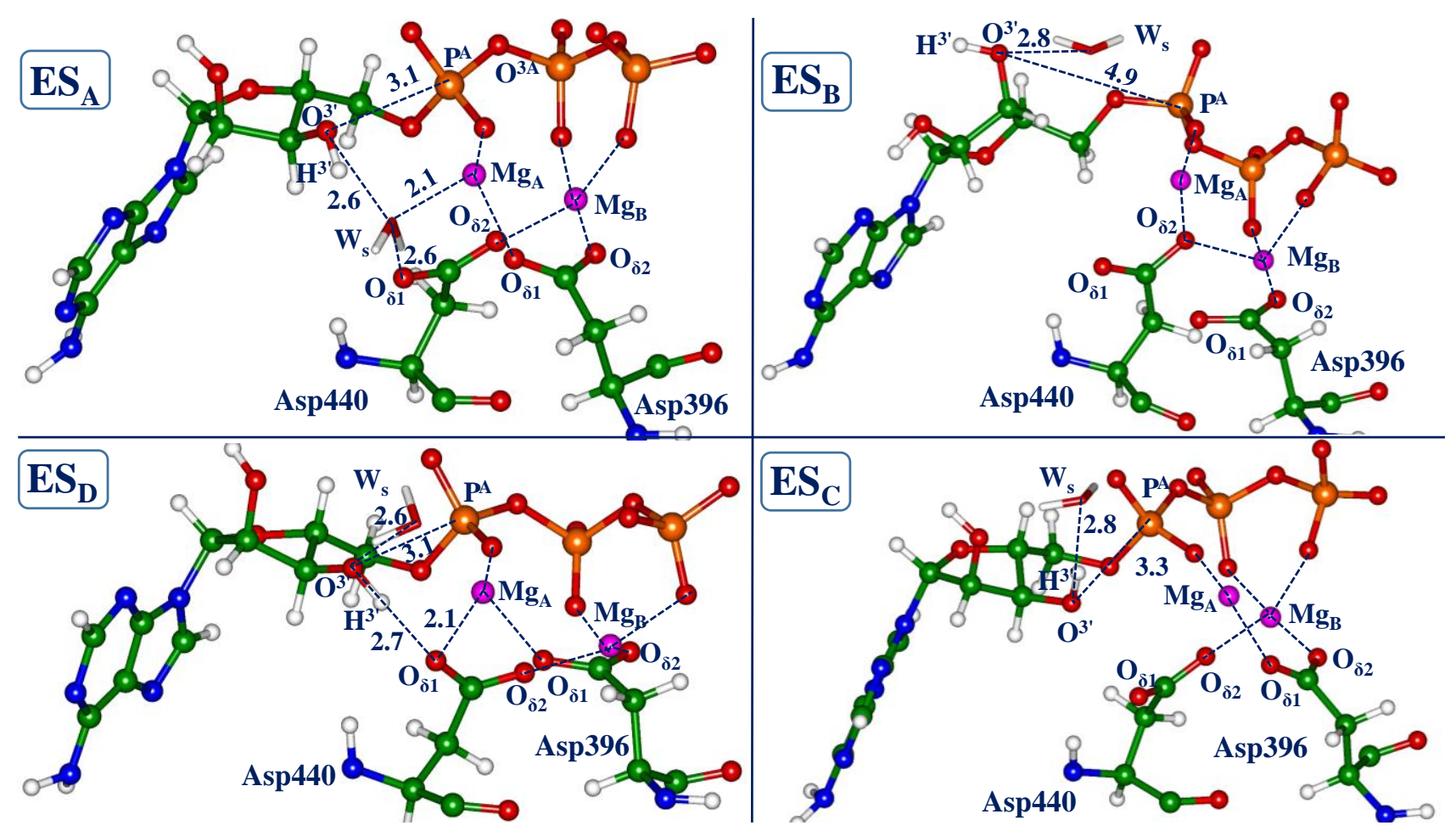

Figure 3. Structures of the lowest energy enzyme-substrate complexes located in the present QM/MM simulations. In each structure, a water molecule which is conveniently located to accept the $\mathrm{H}^{3^{\prime}}$ proton is shown in sticks. Distances in this and all other figures below are given in $\AA$. 
Table 1. Relative energies (kcal/mol) and selected distances $(\AA)$ in the ES structures (Fig. 3).

\begin{tabular}{|l|c|c|c|c|}
\hline Property & $\mathrm{ES}_{\mathrm{A}}$ & $\mathrm{ES}_{\mathrm{B}}$ & $\mathrm{ES}_{\mathrm{C}}$ & $\mathrm{ES}_{\mathrm{D}}$ \\
\hline $\mathrm{QM} / \mathrm{MM}$ energy & 0 & 4.9 & 10.4 & 14.2 \\
\hline $\mathrm{O}^{3}-\mathrm{P}^{\mathrm{A}}$ & 3.12 & 4.87 & 3.28 & 3.15 \\
\hline $\mathrm{Mg}_{\mathrm{A}}-\mathrm{O}_{\delta 1}($ Asp440) & 3.84 & 3.07 & 3.80 & 2.14 \\
\hline $\mathrm{Mg}_{\mathrm{A}}-\mathrm{O}_{\delta 2}$ (Asp440) & 3.64 & 2.19 & 3.49 & 2.98 \\
\hline $\mathrm{Mg}_{\mathrm{A}^{-}} \mathrm{O}^{3^{\prime}}$ & 3.78 & 5.70 & 3.04 & 2.74 \\
\hline
\end{tabular}

Structures with the lowest energies are considered as likely candidates for productive ES conformations to initiate a reaction pathway. In this respect, the $\mathrm{ES}_{\mathrm{A}}$ structure (the left upper panel in Fig. 3) seems preferable. The $\mathrm{O}^{3^{\prime}}-\mathrm{P}^{\mathrm{A}}$ distance of $3.12 \AA$ benefits a nucleophilic $\mathrm{O}^{3^{\prime}}$ attack on $\mathrm{P}^{\mathrm{A}}$; a perspective shuttling water molecule $\mathrm{W}_{\mathrm{s}}$ is perfectly hydrogen bonded to the $\mathrm{O}^{3^{\prime}}$ and $\mathrm{O}_{\delta 1}(\mathrm{Asp} 440)$ atoms with the $\mathrm{O}^{3}-\mathrm{O}_{\mathrm{w}}$ and $\mathrm{O}_{\mathrm{w}^{-}} \mathrm{O}_{\delta 1}($ Asp440) distances $2.65 \AA$ and $2.57 \AA$, respectively. This water molecule $\mathrm{W}_{\mathrm{s}}$ enters the coordination shell of $\mathrm{Mg}_{\mathrm{A}}{ }^{2+}$ with a short $\mathrm{Mg}-\mathrm{O}_{\mathrm{w}}$ distance $2.11 \AA$. This rigid construct favors an efficient proton translocation from the $\mathrm{O}^{3 \prime} \mathrm{H}^{3^{\prime}}$ group to Asp440 via $\mathrm{W}_{\mathrm{s}}$.

Structures $\mathrm{ES}_{\mathrm{B}}$ and $\mathrm{ES}_{\mathrm{C}}$ lying about 5 and $10 \mathrm{kcal} / \mathrm{mol}$ higher in energy than $\mathrm{ES}_{\mathrm{A}}$ exhibit a different orientation of the $\mathrm{O}^{3} \mathrm{H}^{3}$ group. We shall consider below a possible reaction pathway initiated from $\mathrm{ES}_{\mathrm{C}}$. Although the $\mathrm{ES}_{\mathrm{B}}$ structure is energetically close to $\mathrm{ES}_{\mathrm{A}}$, the $\mathrm{O}^{3^{\prime}}$ and $\mathrm{P}^{\mathrm{A}}$ atoms stand too far from each other (almost $5 \AA$ ) to expect a favorable nucleophilic attack.

Our interest to the structure $\mathrm{ES}_{\mathrm{D}}$ (the left bottom panel in Fig. 3), which lies about 14 $\mathrm{kcal} / \mathrm{mol}$ higher than $\mathrm{ES}_{\mathrm{A}}$, is explained by the following reasons. This is the only complex, containing a structural motif observed in crystallography studies ${ }^{6,23}$ of the "crossed" coordination bonds $\left(\mathrm{O}_{\delta 1}(\mathrm{Asp} 440)-\mathrm{Mg}_{\mathrm{A}}-\mathrm{O}_{\delta 1}(\mathrm{Asp} 396)\right.$ and $\left.\mathrm{O}_{\delta 2}(\mathrm{Asp} 440)-\mathrm{Mg}_{\mathrm{B}}-\mathrm{O}_{\delta 2}(\mathrm{Asp} 396)\right)$ between both aspartic acids and magnesium ions. The close $\mathrm{O}^{3}-\mathrm{P}^{\mathrm{A}}$ distance of $3.15 \AA$ is practically the same as in structure $\mathrm{ES}_{\mathrm{A}}$. Moreover, we found that the $\mathrm{ES}_{\mathrm{D}}$ structure closely resembles the reactive 
conformation described in Ref 4. In the next subsection we compare these two ES complexes derived in different computational works.

\section{Comparison of ES structures derived from different computations}

We denote here the model system described in Ref 4 as ES'. Atomic coordinates of the latter are available in Table S2 in Supporting Information in Ref 4. Fig. 4 shows superposition of a fragment of the $\mathrm{ES}_{\mathrm{D}}$ and $\mathrm{ES}^{\prime}$ complexes aligned by coordinates of the $\mathrm{C} \alpha$ atoms in Arg484, Arg1029, Lys 1065 (see Fig. 2). The ES $\mathrm{D}_{\mathrm{D}}$ system is shown in colored balls and sticks, the ES' system is shown in yellow sticks.

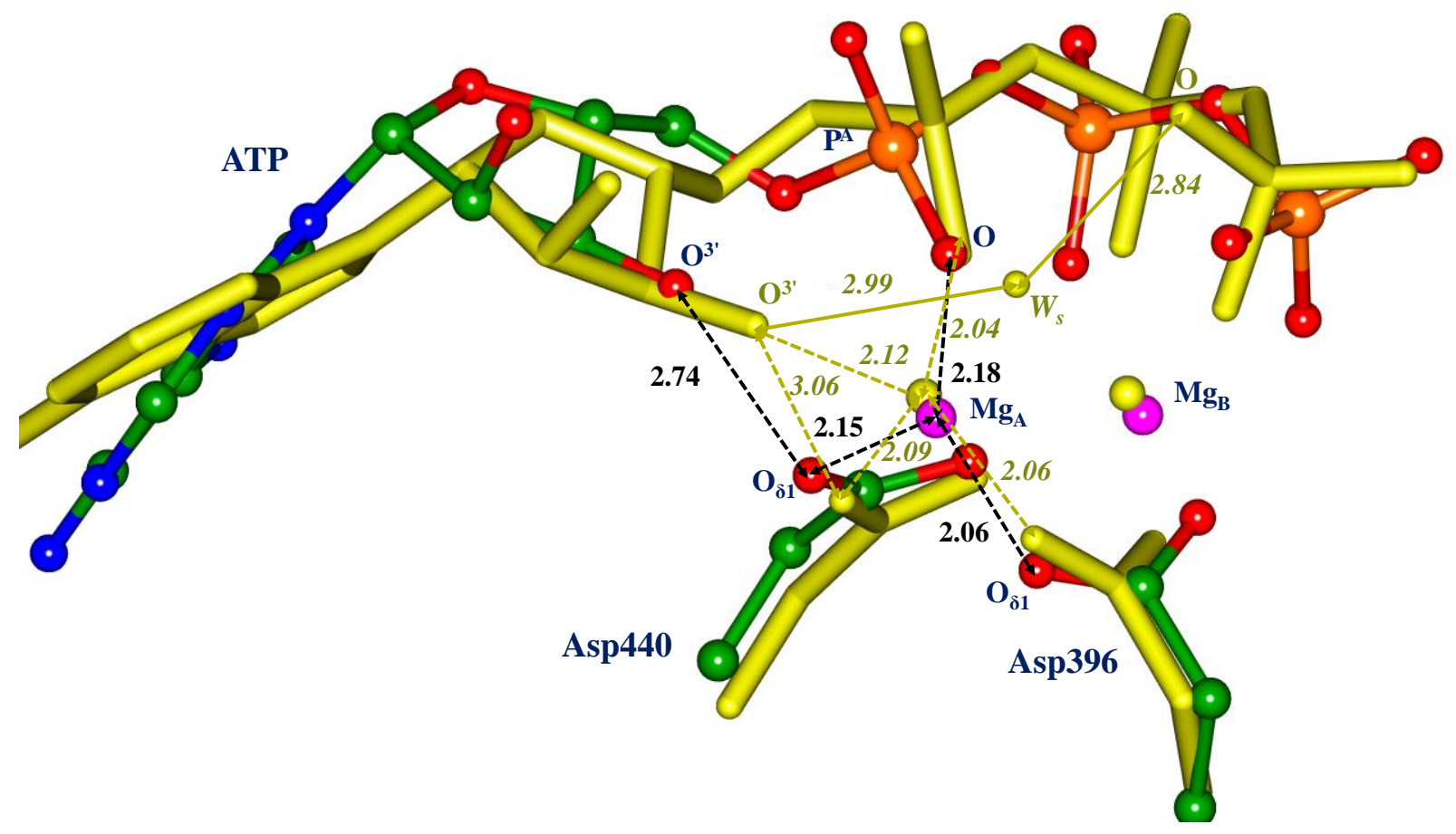

Figure 4. Superposition of structures of enzyme-substrate complexes for two computationally derived model systems, $\mathrm{ES}^{\prime}$ and $\mathrm{ES}_{\mathrm{D}}$. Hydrogen atoms are not shown. Colored balls and sticks show the result of the present study $\left(\mathrm{ES}_{\mathrm{D}}\right)$, yellow sticks refer to the model of Ref 4 (ES'). Black dashed arrows and black characters refer to $\mathrm{ES}_{\mathrm{D}}$, yellow arrows and characters refer to $\mathrm{ES}$ '. 
As seen in Fig. 4, conformations of the side chains of Asp396 and Asp440, the phosphate groups in ATP and coordination shells of magnesium ions are fairly close in $\mathrm{ES}_{\mathrm{D}}$ and ES' in spite of different computational protocols used to construct these model systems from the same crystal structure PDB ID 1CJK, ${ }^{6} \mathrm{QM}(\mathrm{M} 06) / \mathrm{PCM}$ in Ref 4 and QM(PBE0)/MM(AMBER) in this work.

We draw a special attention to the coordination shell of $\mathrm{Mg}_{\mathrm{A}}$. First, we note a coordination bond between $\mathrm{Mg}_{\mathrm{A}}$ and $\mathrm{O}_{\delta 1}$ atom of Asp440 in both systems; the corresponding $\mathrm{O}-\mathrm{Mg}$ distances are $2.09 \AA$ in $E S^{\prime}$ and $2.15 \AA$ in $\mathrm{ES}_{\mathrm{D}}$. Also, the coordination bonds of $\mathrm{Mg}_{\mathrm{A}}{ }^{2+}$ with the oxygen atom of $\alpha-$ phosphate $\left(2.04 \AA\right.$ in $\mathrm{ES}^{\prime}$ and $2.18 \AA$ in $\left.\mathrm{ES}_{\mathrm{D}}\right)$ and $\mathrm{O}_{\delta 1}$ from $\mathrm{Asp} 396(2.06 \AA$ in both systems $)$ are similar. However, an orientation of the ribose fragment with respect to the $\mathrm{Mg}_{\mathrm{A}}-\mathrm{Asp} 440$ pair in ES' notably differs from that in $\mathrm{ES}_{\mathrm{D}}$ : the $\mathrm{O}^{3}-\mathrm{Mg}_{\mathrm{A}}$ distances are $2.12 \AA$ in $\mathrm{ES}^{\prime}$ and $3.24 \AA$ in $\mathrm{ES}_{\mathrm{D}}$, while the $\mathrm{O}^{3^{\prime}}-\mathrm{O}_{\delta 1}(\mathrm{Asp} 440)$ distances are $3.06 \AA$ in $\mathrm{ES}^{\prime}$ and $2.74 \AA$ in $\mathrm{ES}_{\mathrm{D}}$.

A dissimilarity between two models, $\mathrm{ES}^{\prime}$ and $\mathrm{ES}_{\mathrm{D}}$, refers to a treatment of water molecules in the enzyme active site. The authors of Ref 4 consider only two water molecules (recognized in the crystal structure) as explicit quantum groups while impact of other solvent molecules was modeled within the PCM approach. Accordingly, we could find only 5 coordination bonds of $\mathrm{Mg}_{\mathrm{A}}$ in the ES' complex ${ }^{4}$ : four with the oxygen atom $\mathrm{O}^{3}$, the non-bridging oxygen of the $\alpha$-phosphate, the $\mathrm{O}_{\delta 1}$ atoms from Asp396 and Asp440 and one with the oxygen atom from a water molecule $\mathrm{W}_{\mathrm{s}}$ served as a proton shuttle in the mechanism proposed in Ref 4 . In the case of $\mathrm{ES}_{\mathrm{D}}$, more water molecules are present in the active site. As a result, conventional 6 coordination bonds of $\mathrm{Mg}_{\mathrm{A}}{ }^{2+}$ (e.g., Ref 24) are recognized in $\mathrm{ES}_{\mathrm{D}}$ as discussed in the next subsection. Those are the bonds with the ATP oxygen, the $\mathrm{O}_{\delta 1}$ atoms from Asp396 and Asp440 and the oxygen atoms from three water molecules. Unlike ES', the $\mathrm{O}^{3^{\prime}}$ atom is not included into the $\mathrm{Mg}_{\mathrm{A}}$ coordination shell in the $\mathrm{ES}_{\mathrm{D}}$ structure. Despite this difference, the models $\mathrm{ES}_{\mathrm{D}}$ and $\mathrm{ES}$ ' agree that Asp440 is bound by coordination bonds of both $\mathrm{O}_{\delta}$ atoms to $\mathrm{Mg}_{\mathrm{A}}{ }^{2+}$ and $\mathrm{Mg}_{\mathrm{B}}{ }^{2+}$ (as suggested in the crystal structure PDB ID 1CJK). Therefore, Asp440 
is a poor candidate to accept a proton in the proton transfer step in the reaction ATP $\rightarrow$ cAMP, if a reaction pathway is initiated from the $\mathrm{ES}_{\mathrm{D}}$ and $\mathrm{ES}$ ' structures.

We remind that the authors of Ref 4 advocate for the reaction mechanism which assumes a proton transfer along the proton wire from $\mathrm{O}^{3} \mathrm{H}^{3 \prime}$ to the non-bridging $\gamma$-phosphate via the shuttling water molecule as a first elementary step starting from ES'. This route is distinguished in yellow lines and characters in Fig. 4. As mentioned in Introduction, the last step out of five, i.e. the phosphoryl transfer is the rate-determining one with the energy barrier of $17.9 \mathrm{kcal} / \mathrm{mol}$, which is consistent with the observed ${ }^{10}$ rate constant $59 \mathrm{~s}^{-1}$ of the ES $\rightarrow$ EP. The energy barrier at the assumed proton transfer step is fairly large (and compatible with that of the phosphoryl transfer), which may be explained by a relatively large distances between oxygen atoms (almost $3 \AA$, see Fig. 4) along the assumed proton wire.

\section{Magnesium coordination shells in $E S_{A}$ and $E S_{D}$}

We now turn to comparison of the ES structures obtained in this work. Panels in Fig. 5 illustrate structure and dynamics of the $\mathrm{Mg}_{\mathrm{A}}$ coordination shell in the $\mathrm{ES}_{\mathrm{D}}$ (upper row) and $\mathrm{ES}_{\mathrm{A}}$ (bottom row) complexes. We remind that the lowest energy structure $\mathrm{ES}_{\mathrm{A}}$ obtained in the present $\mathrm{QM} / \mathrm{MM}$ simulations lies $14.5 \mathrm{kcal} / \mathrm{mol}$ below the energy level of the $\mathrm{ES}_{\mathrm{D}}$ conformation. 

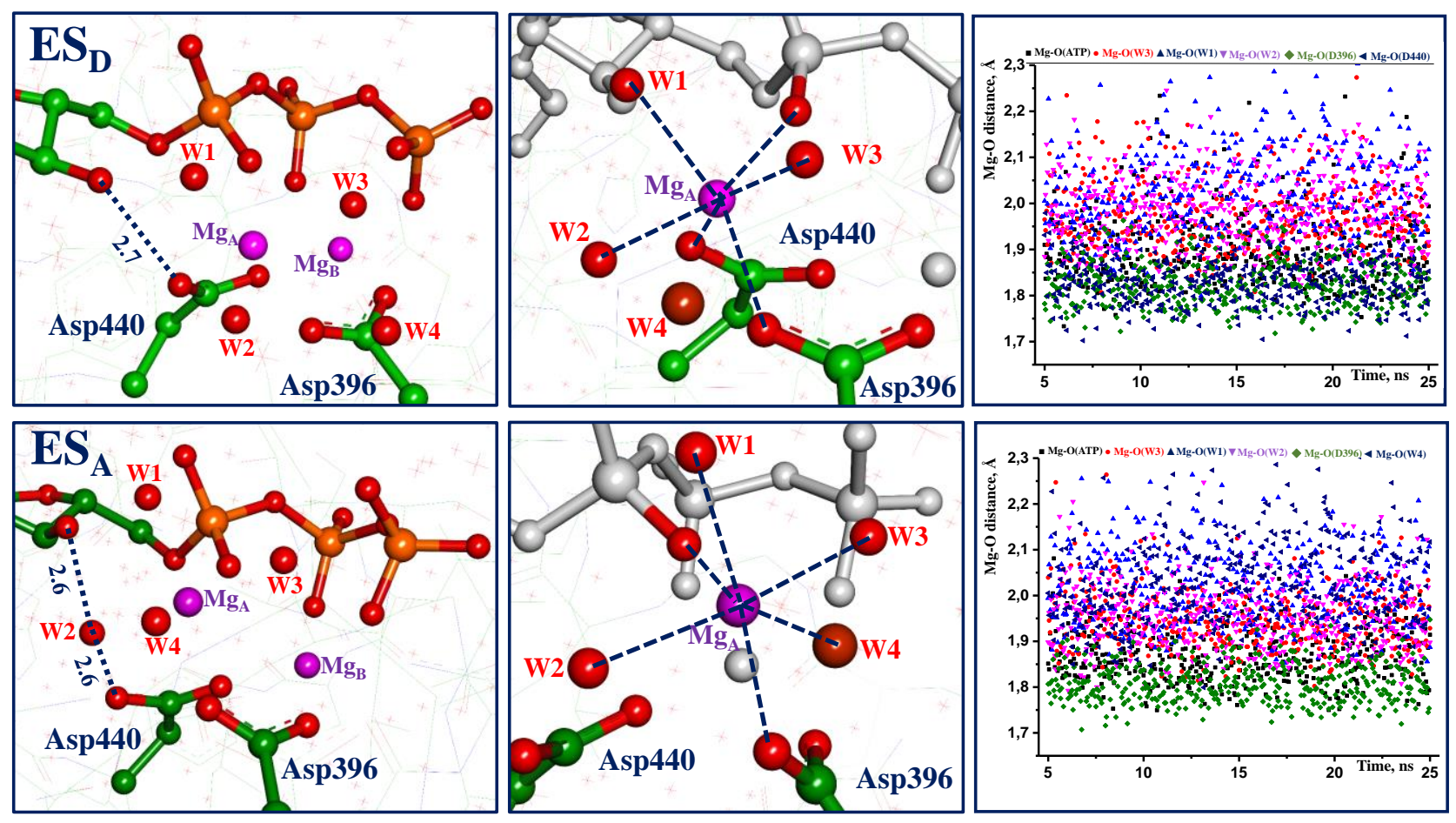

Figure 5. Features of the structures $\mathrm{ES}_{\mathrm{D}}$ (upper row) and $\mathrm{ES}_{\mathrm{A}}$ (bottom row): fragments of the active site (left panels), $\mathrm{Mg}_{\mathrm{A}}{ }^{2+}$ coordination shells (central panels), plots of $\mathrm{Mg}_{\mathrm{A}}-\mathrm{O}$ distances in molecular dynamics trajectories (right panels).

The major difference between $\mathrm{ES}_{\mathrm{A}}$ and $\mathrm{ES}_{\mathrm{D}}$ refers to the coordination shell of $\mathrm{Mg}_{\mathrm{A}}$. Coordination shells of $\mathrm{Mg}_{\mathrm{B}}$ in both complexes include non-bridging oxygen atoms from ATP, $\mathrm{O}_{\delta 2}$ atoms from Asp396 and Asp440, and carbonyl oxygen from Ile397. The shell of $\mathrm{Mg}_{\mathrm{A}}$ shows more interesting features. In $\mathrm{ES}_{\mathrm{A}}$, the coordination bond between $\mathrm{Mg}_{\mathrm{A}}$ and $\mathrm{O}_{\delta 1}(\mathrm{Asp} 440)$ observed in $\mathrm{ES}_{\mathrm{D}}$ (and in the crystal structure PDB ID $1 \mathrm{CJK}{ }^{6}$ ) is replaced by the $\mathrm{Mg}_{\mathrm{A}}-\mathrm{O}$ bond with oxygen from the fourth water molecule in the $\mathrm{Mg}_{\mathrm{A}}$ coordination shell. Comparison of a pair of central panels in Fig. 5 shows that a water molecule denoted $\mathrm{W} 4$, which is outside the $\mathrm{Mg}_{\mathrm{A}}$ coordination shell in $\mathrm{ES}_{\mathrm{D}}$, replaces Asp404 in the $\mathrm{MgA}$ coordination shell in $\mathrm{ES}_{\mathrm{A}}$. In the latter structure, the oxygen atoms of the carboxyl group of Asp404 are coordinated to $\mathrm{Mg}_{\mathrm{B}}$ and to a water molecule (W2) located between $\mathrm{O}^{3^{\prime}}$ and $\mathrm{O}_{\delta 1}(\mathrm{Asp} 404)$. 
It is important to emphasize that both types of the $\mathrm{Mg}_{\mathrm{A}}{ }^{2+}$ coordination shell are stable along MD trajectories. The right panels in Fig. 5 demonstrate that according to MD simulations, all $\mathrm{Mg}_{\mathrm{A}^{-}}$ O distances in both structures are mostly within $1.8 \div 2.1 \AA$. These MD plots are presented in full in Supporting Information (Figs. S3, S4).

The major conclusion is that in the $\mathrm{ES}_{\mathrm{A}}$ conformation, a proton wire over the $\mathrm{O}^{3^{\prime}} \mathrm{H}^{3^{\prime}}-\mathrm{W} 2$ Asp440 chain via a shuttling water molecule (W2 in Fig. 5 or $\mathrm{W}_{\mathrm{s}}$ in Fig. 3) in the enzyme active site provides a relevant proton route to deprotonate $\mathrm{O}^{3^{\prime}}$ and to facilitate its nucleophilic attack on $\mathrm{P}^{\mathrm{A}}$. Possible reaction pathways initiated from $\mathrm{ES}_{\mathrm{D}}$ may include other proton wires similar to that described in Ref 4.

\section{The reaction mechanism initiated by the $\mathrm{ES}_{A}$ conformation}

We found that no reaction intermediates occur along the reaction route $\mathrm{ES}_{\mathrm{A}} \rightarrow \mathrm{TS} \rightarrow \mathrm{EP}$. The panels in Fig. 6 illustrate principal structural features of the stationary points as well as the computed energy profile. The two-dimensional relaxed scan on the energy surface along coordinates corresponding to the $\mathrm{O}^{3}-\mathrm{P}^{\mathrm{A}}$ and $\mathrm{P}^{\mathrm{A}}-\mathrm{O}^{3 \mathrm{~A}}$ distances allowed us to locate vicinity of the saddle point separating ES and the enzyme-product (EP) complex containing cAMP and PPi. Structure of the transition state (TS) was located in series of constrained QM/MM minimizations, finally exploring the coordinate $\mathrm{O}^{3}-\mathrm{P}^{\mathrm{A}}$. Multiple passages in the forward and backward directions between the ES, TS and EP points including gradual descent form TS allowed us to verify that the true saddle point were found.

Changes in geometry parameters along the pathway (see Fig. 6) are typical for phosphoryl transfer reactions with the penta-coordinated phosphorus atom in the TS configuration (e.g., those observed in Ref 5). 

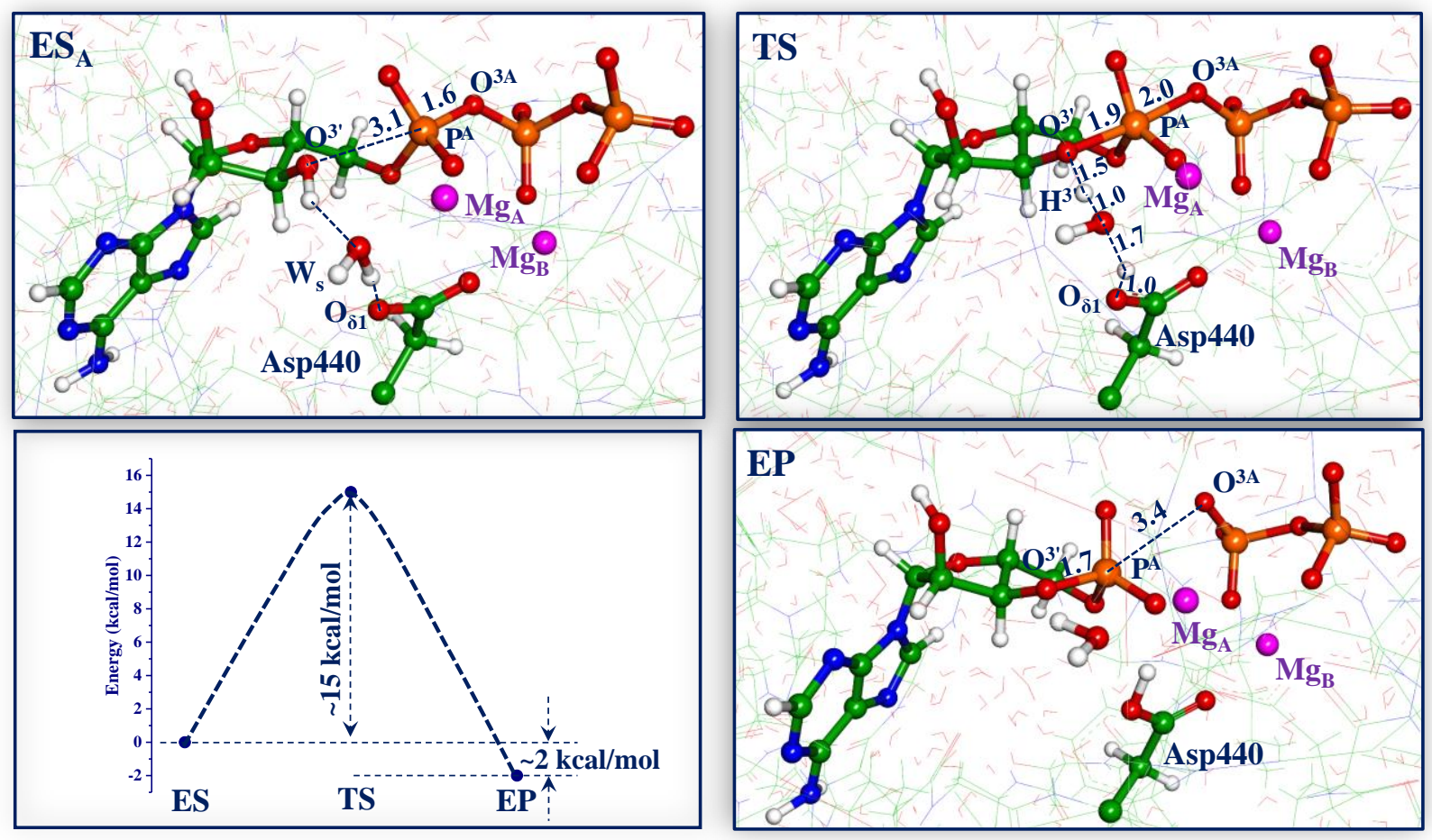

Figure 6. The reaction pathway initiated from the lowest energy enzyme-substrate structure $\mathrm{ES}_{\mathrm{A}}$.

The estimated energy profile (left bottom panel in Fig. 6) is consistent with the observed rate constants of $59 \mathrm{~s}-1(\sim 15.1 \mathrm{kcal} / \mathrm{mol})$ for the forward reaction and $2.6 \mathrm{~s}-1(\sim 17 \mathrm{kcal} / \mathrm{mol})$ for the backward reaction. ${ }^{10}$ Our computational data refer to the potential energy surface, but we do not expect dramatic changes in conclusions if this energy profile is corrected to obtain the free energy profile. First, chemical transformations within a fairly rigid construct of the molecular groups in the active site (see the left upper panel in Fig. 3) should not lead to large entropic corrections. Second, we refer to the results of previous simulations ${ }^{4}$ carried out for another reaction route in the same system, showing that differences between potential energy and free energy reliefs are not critical for characterization of the mechanism. 


\section{The reaction mechanism initiated by the $\mathrm{ES}_{C}$ conformation}

Other candidates for the initial starting point on the reaction pathway, which are shown in Fig. 3, are characterized by higher energies computed in the present QM/MM simulations. In this subsection, we consider the structure $\mathrm{ES}_{\mathrm{C}}$, which lies about $10 \mathrm{kcal} / \mathrm{mol}$ higher in energy than $\mathrm{ES}_{\mathrm{A}}$. Like in $\mathrm{ES}_{\mathrm{A}}$, there is no coordination bond between $\mathrm{Mg}_{\mathrm{A}}$ and $\mathrm{O}_{\delta 1}(\mathrm{Asp} 440)$; however, as seen in the left upper panel in Fig. 7, orientation of the $\mathrm{O}^{3} \mathrm{H}^{3 \prime}$ group does not favor a proton transfer route to $\mathrm{O}_{\delta 1}($ Asp440).
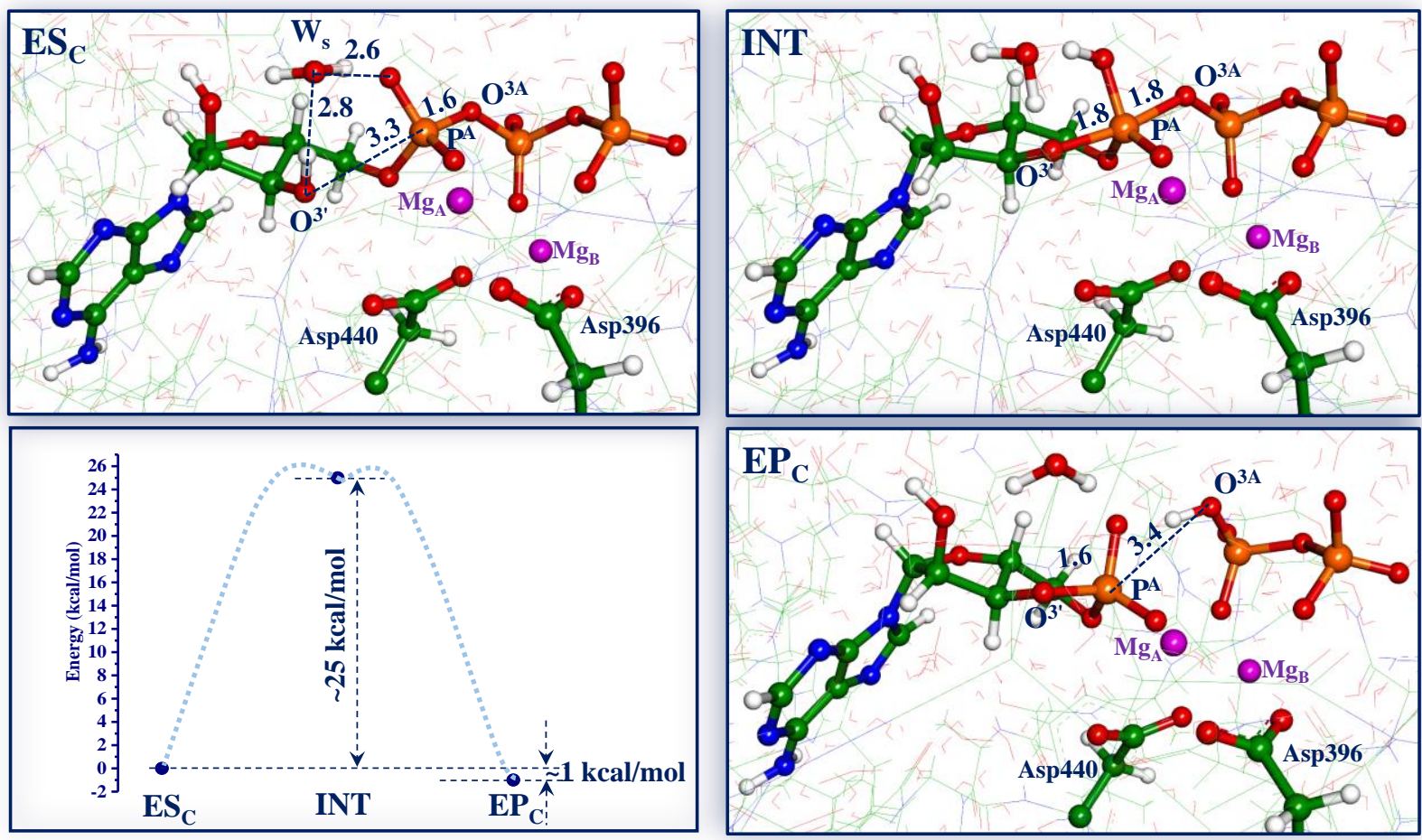

Figure 7. The reaction mechanism initiated from $\mathrm{ES}_{\mathrm{C}}$. The dotted light blue curves in the left bottom panel connecting the points $\mathrm{ES}_{\mathrm{C}}, \mathrm{INT}$ and $\mathrm{EP}_{\mathrm{C}}$ are drawn manually to guide the eye.

However, in this case another proton wire connects the $\mathrm{O}^{3} \mathrm{H}^{3 \prime}$ group with a perspective proton acceptor, a non-bridging oxygen atom in the $\alpha$-phosphate via a shuttling water molecule denoted $\mathrm{W}_{\mathrm{s}}$ in Fig. 7. We explored an intensive search on the energy surface and found a local minimum energy point INT shown in the right upper panel in Fig. 7. This reaction intermediate 
exhibits a familiar structural motif of the penta-coordinated phosphorus moiety. Elongation of the $\mathrm{P}^{\mathrm{A}}-\mathrm{O}^{3 \mathrm{~A}}$ distance led to the valley of the reaction products, cAMP and PPi, shown in the right bottom panel in Fig. 7. In this case it is enough to consider the relative energies of the points $\mathrm{ES}_{\mathrm{C}}$, INT and $\mathrm{EP}_{\mathrm{C}}$ (left bottom panel in Fig. 7); apparently the activation barrier for the forward reaction must be higher than the level of INT ( $25 \mathrm{kcal} / \mathrm{mol})$. This result is consistent with a remark in Ref 3 that proton transfer from the 3 '-OH nucleophile to the $\alpha$-phosphate non-bridging oxygen "is associated with a very high activation barrier [as] in a related nucleotidyl transfer reaction ${ }^{25,}$.

\section{The reaction mechanism for the Asp440Ala mutant}

According to experimental studies, ${ }^{6}$ mutation of Asp440 by Ala (or Asn) reduces activity of the enzyme with respect to ATP to cAMP conversion approximately 2000 times. By this reason, the authors of Ref 6 conclude that Asp440 is unlikely to be a general base because its replacement maintains enzyme activity. To explore a possible reaction mechanism in the Asp440Ala mutant of AC we created a model system manually replacing the side chain of Asp440 by Ala in the previously $\mathrm{QM} / \mathrm{MM}$ optimized $\mathrm{ES}_{\mathrm{A}}$ conformation and re-optimized geometry parameters of the system using similar MD and QM/MM protocols as described above. The obtained structure denoted $\mathrm{ES}_{\mathrm{Ala}}$ is shown in the left upper panel in Fig. 8. Because of a smaller size of Ala as compared to Asp, additional water molecules are observed in the cavity as compared to the wildtype enzyme.

In the $\mathrm{ES}_{\mathrm{Ala}}$ structure, we recognize a new proton wire connecting the ribose $\mathrm{O}^{3} \mathrm{H}^{3^{\prime}}$ group with a non-bridging oxygen of the $\alpha$-phosphate via the chain of properly oriented two water molecules denoted $\mathrm{W}_{\mathrm{s} 1}$ and $\mathrm{W}_{\mathrm{s} 2}$ in Fig. 8. Consideration of concerted proton transfer along this wire allowed us to locate a minimum energy point corresponding to the reaction intermediate (the right upper panel) with the penta-coordinated moiety. The energy of the intermediate is about $18 \mathrm{kcal} / \mathrm{mol}$ 
higher than the level of $\mathrm{ES}_{\text {Ala }}$. A careful search of the saddle point separating $\mathrm{ES}_{\mathrm{Ala}}$ and INT resulted in the transition state structure with an energy of $23 \mathrm{kcal} / \mathrm{mol}$ above $\mathrm{ES}_{\mathrm{Ala}}$.
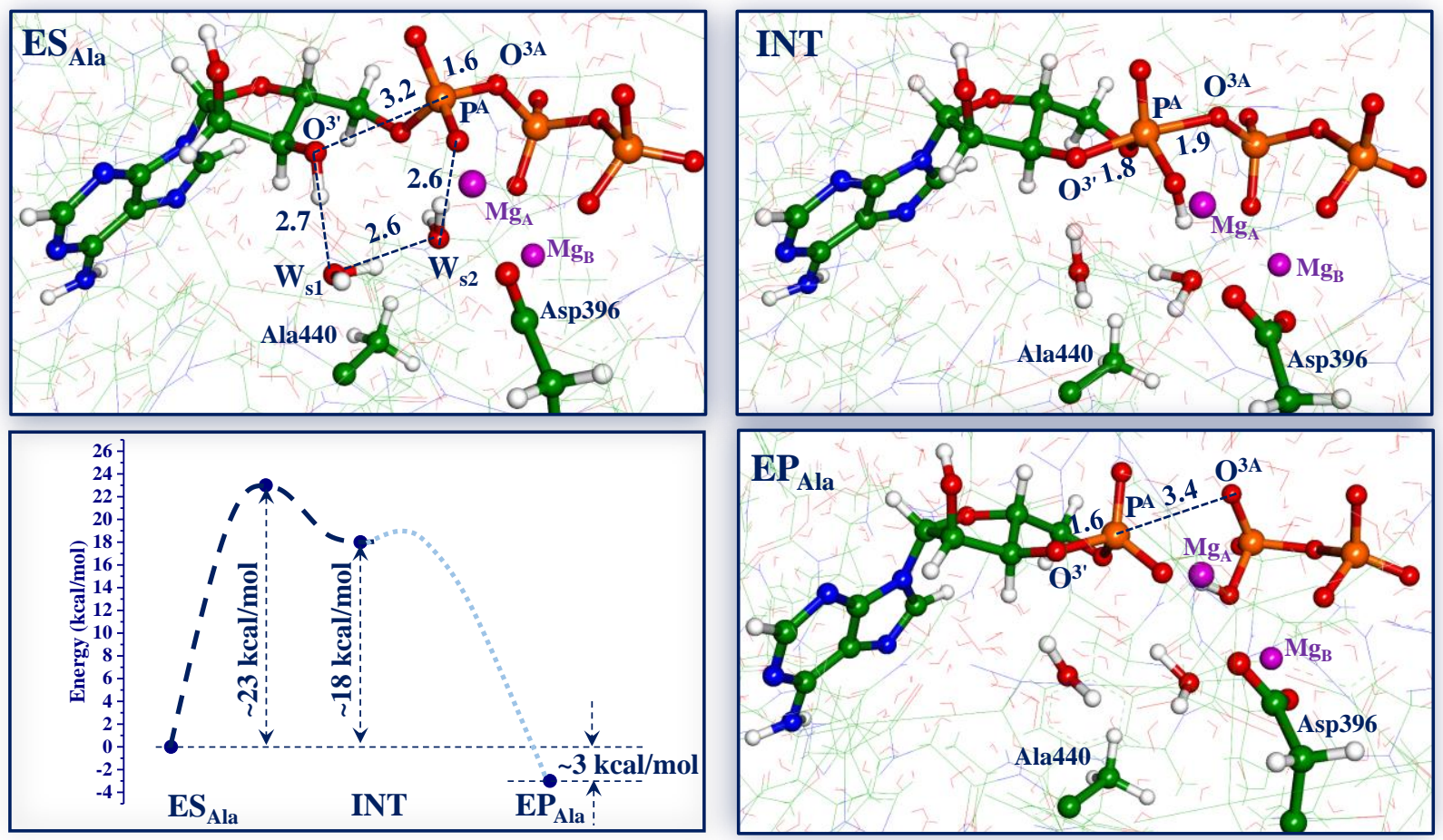

Figure 8. Reaction mechanism in the Asp440Ala mutant. The dotted light blue curves in the left bottom panel connecting the points INT and $\mathrm{EP}_{\text {Ala }}$ are drawn manually to guide the eye.

Taking into consideration that the reaction pathway for the wild-type enzyme $\mathrm{ES}_{\mathrm{A}} \rightarrow \mathrm{TS} \rightarrow \mathrm{EP}$ with an energy barrier of $\sim 15 \mathrm{kcal} / \mathrm{mol}$ and the pathway for the $\mathrm{ES}_{\text {Ala }} \rightarrow \mathrm{TS}_{\mathrm{Ala}} \rightarrow \mathrm{INT}_{\mathrm{Ala}} \rightarrow \mathrm{EP}_{\text {Ala }}$ with a barrier $\sim 23 \mathrm{kcal} / \mathrm{mol}$ are obtained within the same computational protocol, we conclude that our simulations do not exclude the ATP $\rightarrow$ cAMP reaction in the Asp440Ala mutant, but should proceed with a higher energy barrier. From the qualitative side, the reaction mechanism in the Asp440Ala mutant shares common features with all considered scenarios for the wild-type enzyme, suggesting removal of $\mathrm{H}^{3^{\prime}}$ over a proton wire to a proper destination point. 


\section{Summary and additional comments}

We advocate here a one-step reaction pathway for the mammalian $\mathrm{AC}$, which is initiated by the enzyme-substrate structure $\mathrm{ES}_{\mathrm{A}}$. The corresponding minimum energy profile (Fig. 6) shows the lowest energy barrier on the reaction route among those computed for alternative mechanisms. We note, however, that predictions of barrier heights on energy surfaces with conventional DFT-based quantum chemical methods should be considered with a care taking into account typical errors of few kcal/mol. ${ }^{26}$

Our simulations reveal a crucial role of the magnesium coordination shell in the solvent accessible active site in this enzyme. Rephrasing the title of one of the pioneering papers on the AC mechanism ${ }^{23}$ "Mutations uncover a role for two magnesium ions in the catalytic mechanism of adenylyl cyclase" we conclude that simulations underline also a role of coordination shells of magnesium ions in this catalytic mechanism.

In practically all scenarios considered previously and in this work, proton wires facilitating proton release from the ribose $\mathrm{O}^{3} \mathrm{H}^{3}$ group via shuttling water molecules play a role. The importance of proton wires in protein systems is documented in previous works. ${ }^{27-34}$ Simulations described here extend the experience with proton wires in the two-metal catalysis.

\section{Conclusion}

This work contributes to the dispute on the mechanism of one of the most important biochemical reactions, conversion of ATP to cAMP catalyzed by adenylyl cyclases. We report here the following novel aspects of mammalian AC catalysis revealed in MD and QM/MM simulations. We show that the lowest energy ES structure, in which the coordination shell of the $\mathrm{Mg}_{\mathrm{A}}{ }^{2+}$ ion does not include the side chain of the critical Asp440 residue, initiate a plausible reaction pathway. Its essential feature is a proton transfer from the ribose group $\mathrm{O}^{3^{\prime}} \mathrm{H}^{3^{\prime}}$ group to Asp440 via a shuttling 
water molecule, concerted with $\mathrm{P}^{\mathrm{A}}-\mathrm{O}^{3 \mathrm{~A}}$ bond cleavage and $\mathrm{O}^{3^{\prime}}-\mathrm{P}^{\mathrm{A}}$ bond formation. The computed QM/MM energy profile for this route is consistent with the rate constants known from experimental kinetics studies, although we do not pretend here for quantitative conclusions. Other conformations of ES correspond to higher energy model systems, and do not suggest convincing low-energy proton translocation routes from $\mathrm{O}^{3} \mathrm{H}^{3^{\prime}}$ to facilitate the nucleophilic attack of $\mathrm{O}^{3 \prime}$ on the $\mathrm{P}^{\mathrm{A}}$ atom. In the case of AC mutant Asp440Ala, the estimated energy profile is consistent with observations of lower activity relative to the wild-type enzyme.

\section{Acknowledgement}

This work was supported by the Russian Science Foundation (project 19-73-20032). The research is carried out using the equipment of the shared research facilities of HPC computing resources at Lomonosov Moscow State University supported by the project RFMEFI62117X0011. The use of supercomputer resources of the Joint Supercomputer Center of the Russian Academy of Sciences is also acknowledged.

Supporting Information is available containing additional figures (Figs. S1 - S4). 


\section{References}

(1) Patel, T. B.; Du, Z.; Cartin, P. S.; Scholich, K. Molecular Biological Approaches to Unravel Adenylyl Cyclase Signaling and Function. Gene 2001, 269, 13-25.

(2) Schmid, A.; Meili, D.; Salathe, M. Soluble Adenylyl Cyclase in Health and Desease. Biochim Biophys Acta 2014, 1842, 2584-2592.

(3) Mones, L.; Tang, W.-J.; Florian, J. (2013) Empirical Valence Bond Simulations of the Chemical Mechanism of ATP to cAMP Conversion by Anthrax Edema Factor. Biochemistry 2013, 52, 2672-2682.

(4) Hahn, D. K.; Tusell, J. R.; Sprang, S. R.; Chu, X. Catalytic Mechanism of Mammalian Adenylyl Cyclase: A Computational Investigation. Biochemistry 2015, 54, 6252-6262.

(5) Jara, G. E.; Martínez, L. Anthrax Edema Factor: An Ion-Adaptive Mechanism of Catalysis with Increased Transition State Conformational Flexibility. J Phys Chem B 2016, 120, 65046514.

(6) Tesmer, J.J.G., Sunahara, R. K., Johnson, R.A., Gosselin, G., Gilman, A.G., Sprang, S.R. Two-Metal-Ion Catalysis in Adenylyl Cyclase. Science 1999, 285, 756-760.

(7) Warshel, A.; Weiss, R. M. An Empirical Valence Bond Approach for Comparing Reaction in Solutions and in Enzymes. J Am Chem Soc 1980, 102, 6218-6226.

(8) Cui, Q.; Elstner, M.; Kaxiras, E.; Frauenheim, T.; Karplus, M. A QM/MM Implementation of the Self-Consistent Charge Density Functional Tight Binding (SCC-DFTB) Method. J Phys Chem B 2001, 105, 569-585.

(9) Cai, Z.-L.; Lopez, P.; Reimers, J. R.; Cui, Q.; Elstner, M. Application of the Computationally Efficient Self-Consistent-Charge Density-Functional Tight-Binding Method to Magnesium-Containing Molecules. J Phys Chem A 2007, 111, 5743-5750.

(10) Dessauer, C. W., Gilman, A. G. The Catalytic Mechanism of Adenylyl Cyclase. Equilibrium Binding and Kinetic Analysis of P-Site Inhibition. J Biol Chem 1997, 272, 27787-27795.

(11) Liu, Y.; Ruoho, A.E.; Rao, V. D.; Hurley, J. H. Catalytic Mechanism of the Adenylyl and Guanylyl Cyclases: Modeling and Mutational Analysis. Proc Natl Acad Sci USA 1997, 94, 13414-13419.

(12) Phillips, J. C.; Braun, R.; Wang, W.; Gumbart, J.; Tajkhorshid, E.; Villa, E.; Chipot, C.; Skeel, R. D.; Kalé, L.; Schulten, K. Scalable Molecular Dynamics with NAMD. J Comput Chem 2005, 26 (16), 1781-1802.

(13) MacKerell, A. D.; Bashford, D.; Bellott, M.; Dunbrack, R. L.; Evanseck, J. D.; Field, M. J.; Fischer, S.; Gao, J.; Guo, H.; Ha, S.; et al. All-Atom Empirical Potential for Molecular Modeling and Dynamics Studies of Proteins. J Phys Chem B 1998, 102 (18), 3586-3616. 
(14) Komuro, Y.; Re, S.; Kobayashi, C.; Muneyuki, E.; Sugita, Y. CHARMM Force-Fields with Modified Polyphosphate Parameters Allow Stable Simulation of the ATP-Bound Structure of $\mathrm{Ca}^{2+}$-ATPases. J Chem Theor Comput 2014, 10, 4133-4142.

(15) Warshel, A.; Levitt, M. Theoretical Studies of Enzymic Reactions: Dielectric, Electrostatic and Steric Stabilization of the Carbonium Ion in the Reaction of Lysozyme. J Mol Biol 1976, 103 (2), 227-249.

(16) Senn, H. M.; Thiel, W. QM/MM Methods for Biomolecular Systems. Angew Chemie Int Ed 2009, 48 (7), 1198-1229.

(17) Merz, K. M. Using Quantum Mechanical Approaches to Study Biological Systems. Acc Chem Res 2014, 47, 2804-2811.

(18) van der Kamp, M. V.; Mulholland, A. J. Combined Quantum Mechanics/Molecular Mechanics (QM/MM) Methods in Computational Enzymology. Biochemistry 2013, 52, 2708-2728.

(19) Adamo, C.; Barone, V. Toward Reliable Density Functional Methods without Adjustable Parameters: The PBE0 Model. J Chem Phys 1999, 110 (13), 6158.

(20) Grimme, S.; Antony, J.; Ehrlich, S.; Krieg, H. A Consistent and Accurate Ab Initio Parametrization of Density Functional Dispersion Correction (DFT-D) for the 94 Elements HPu. J Chem Phys 2010, 132 (15), 154104.

(21) Cornell, W. D.; Cieplak, P.; Bayly, C. I.; Gould, I. R.; Merz, K. M.; Ferguson, D. M.; Spellmeyer, D. C.; Fox, T.; Caldwell, J. W.; Kollman, P. A. A Second Generation Force Field for the Simulation of Proteins, Nucleic Acids, and Organic Molecules. J Am Chem Soc 1995, 117 (19), 5179-5197.

(22) Valiev, M.; Bylaska, E. J.; Govind, N.; Kowalski, K.; Straatsma, T. P.; Van Dam, H. J. J.; Wang, D.; Nieplocha, J.; Apra, E.; Windus, T. L.; et al. NWChem: A Comprehensive and Scalable Open-Source Solution for Large Scale Molecular Simulations. Comput Phys Commun 2010, 181 (9), 1477-1489.

(23) Zimmermann, G.; Zhou, D.; Taussig, R. Mutations Uncover a Role for Two Magnesium Ions in the Catalytic Mechanism of Adenylyl Cyclase. J Biol Chem 1998, 273, 19650-19655.

(24) Bock, C. W.; Kaufman, A.; Glusker, J. P. Coordination of Water to Magnesium Cations. Inorg Chem 1994, 33, 419-427.

(25) Florian, J.; Goodman, M. F.; Warshel, A. Computer Simulation of the Chemical Catalysis of DNA Polymerases: Discriminating between Alternative Nucleotide Insertion Mechanisms for T7 DNA Polymerase. J Am Chem Soc 2003, 125, 8163-8177.

(26) Mardirossian, N.; Head-Gordon, M. Thirty Years of Density Functional Theory in Computational Chemistry: An Overview and Extensive Assessment of 200 Density 
Functionals. Mol Phys 2017, 115 (19), 2315-2372.

(27) Brewer, M. L.; Schmitt, U. W.; Voth, G. A. The Formation and Dynamics of Proton Wires in Channel Environments. Biophys J 2001, 80, 1691-1702.

(28) Nemukhin, A. V.; Grigorenko, B. L.; Topol, I. A.; Burt, S. K. Quantum Chemical Simulations of the Proton Transfer in Water Wires Attached to Molecular Walls. J Phys Chem B 2003, 107, 2958-2965.

(29) Shinobu, A.; Agmon, N. Mapping Proton Wires in Proteins: Carbonic Anhydrase and GFP Chromophore Biosynthesis. J Phys Chem A 2009, 113, 7253-7266.

(30) Shinobu, A.; Palm, G. J.; Schierbeek, A. J.; Agmon, N. Visualizing Proton Antenna in a High-Resolution Green Fluorescent Protein Structure. J Am Chem Soc 2010, 132 (32), 11093-11102.

(31) Morozov, D.; Khrenova, M.; Andrijchenko N.; Grigorenko, B.; Nemukhin , A. Minimum Energy Reaction Profiles for the Hydrolysis Reaction of the Cyclic Guanosine Monophosphate in Water: Comparison of the Results of Two QM/MM Approaches. Comput Theor Chem 2012, 983, 88-94.

(32) Grigorenko, B. L.; Nemukhin, A. V.; Polyakov, I. V.; Morozov, D. I.; Krylov, A. I. FirstPrinciples Characterization of the Energy Landscape and Optical Spectra of Green Fluorescent Protein along the $\mathrm{A} \rightarrow \mathrm{I} \rightarrow \mathrm{B}$ Proton Transfer Route. J Am Chem Soc 2013, 135 (31), 11541-11549.

(33) Grigorenko, B. L.; Knyazeva, M. A.; Nemukhin, A. V. Analysis of Proton Wires in the Enzyme Active Site Suggests a Mechanism of c-di-GMP Hydrolysis by the EAL Domain Phosphodiesterases. Proteins 2016, 84, 1670-1680.

(34) Shinobu, A.; Agmon, N. Proton Wire Dynamics in the Green Fluorescent Protein. J Chem Theory Comput 2017, 13 (1), 353-369. 


\section{Graphical Abstract}

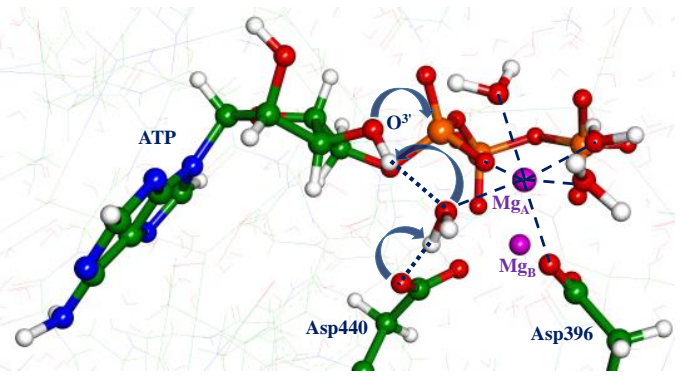




\section{Supporting Information}

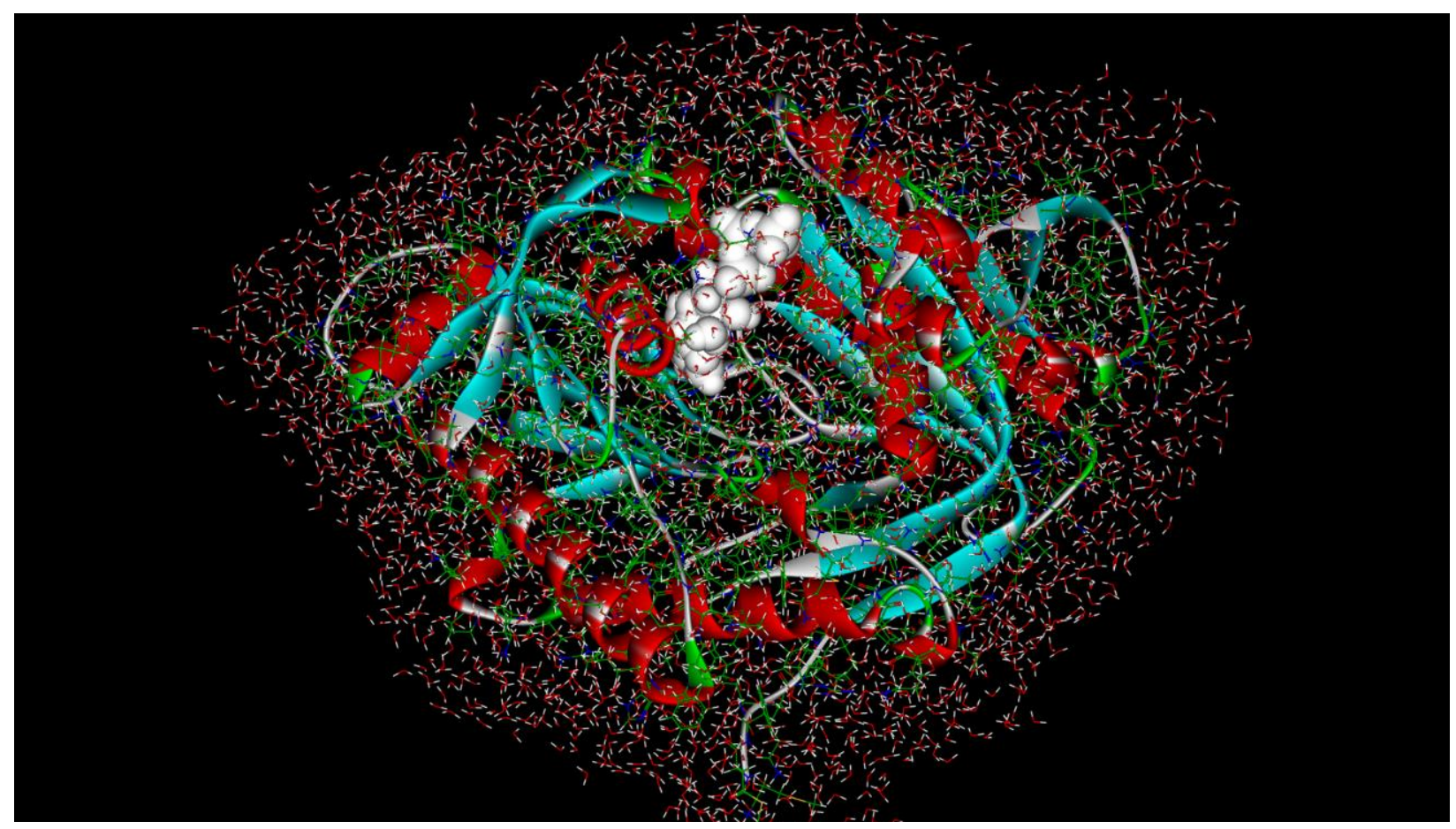

Figure S1. A model system used for simulations of the ATP $\rightarrow$ cAMP reaction in the adenylyl cyclase. The ATP molecule is shown in white filled balls.

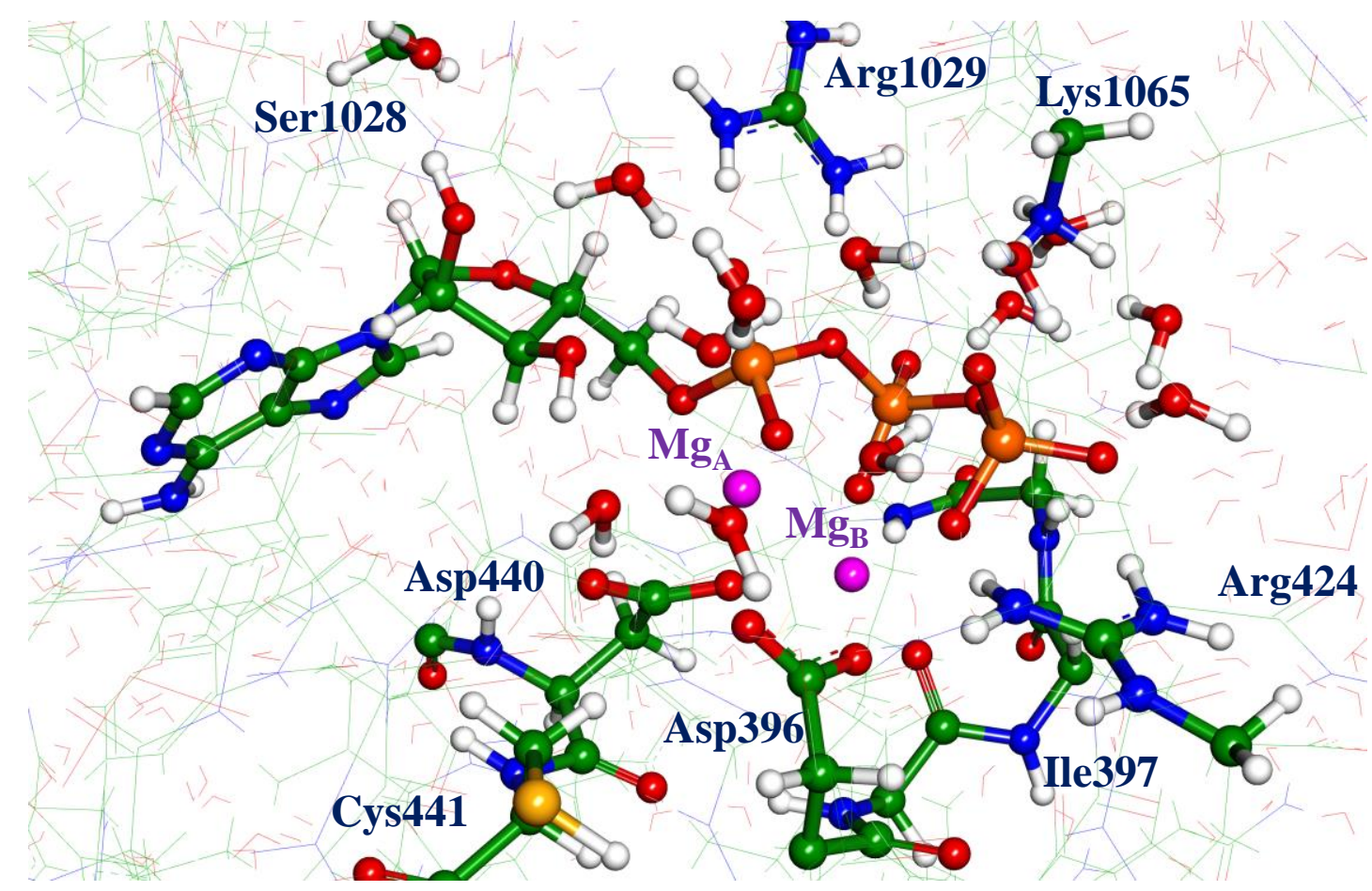

Figure S2. Molecular model of the QM-subsystem used in the present QM/MM simulations. Carbon atoms are drawn in green, oxygen in red, nitrogen in blue, phosphorus in orange, magnesium in magenta. 


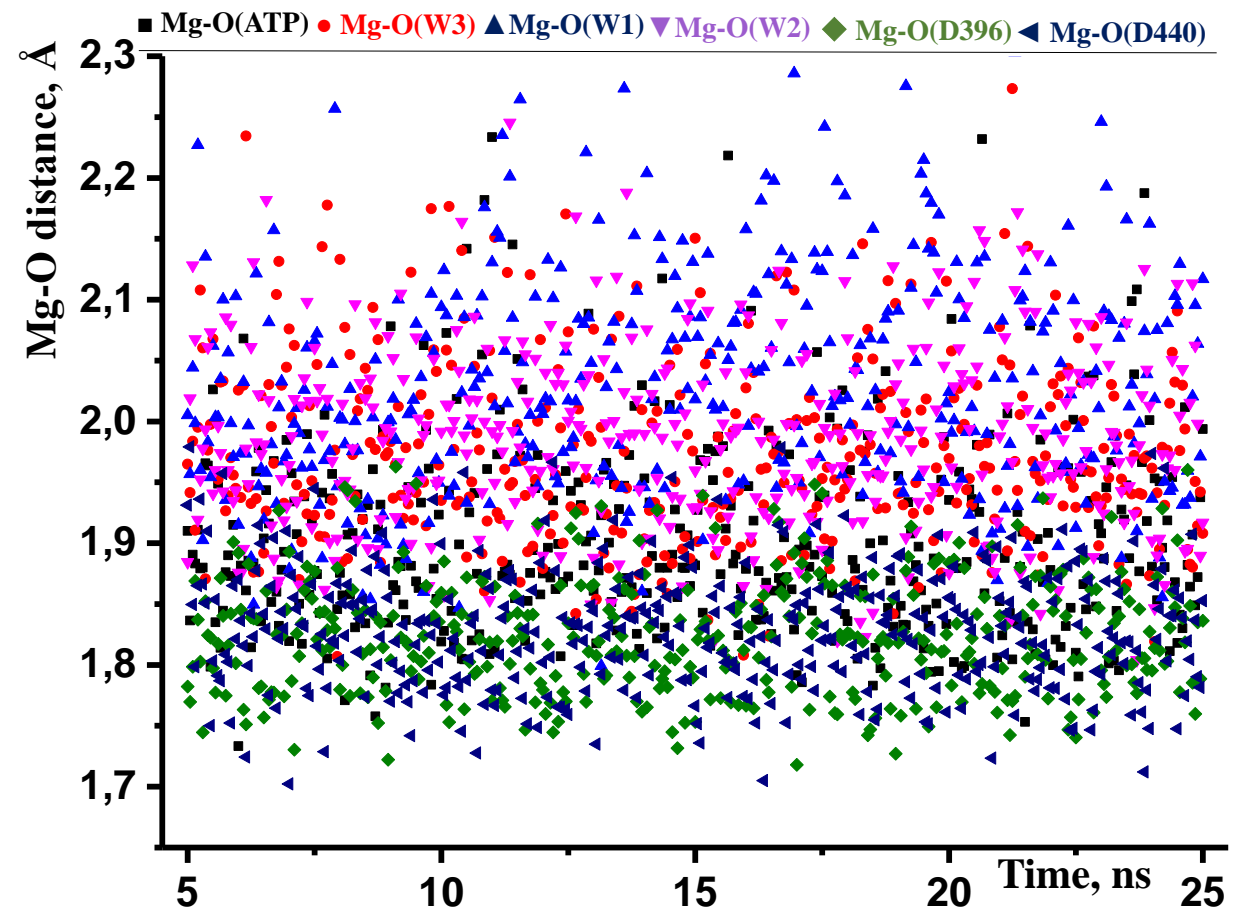

Figure S3. Plot of $\mathrm{Mg}-\mathrm{O}$ distances in the $\mathrm{ES}_{\mathrm{D}}$ structure.

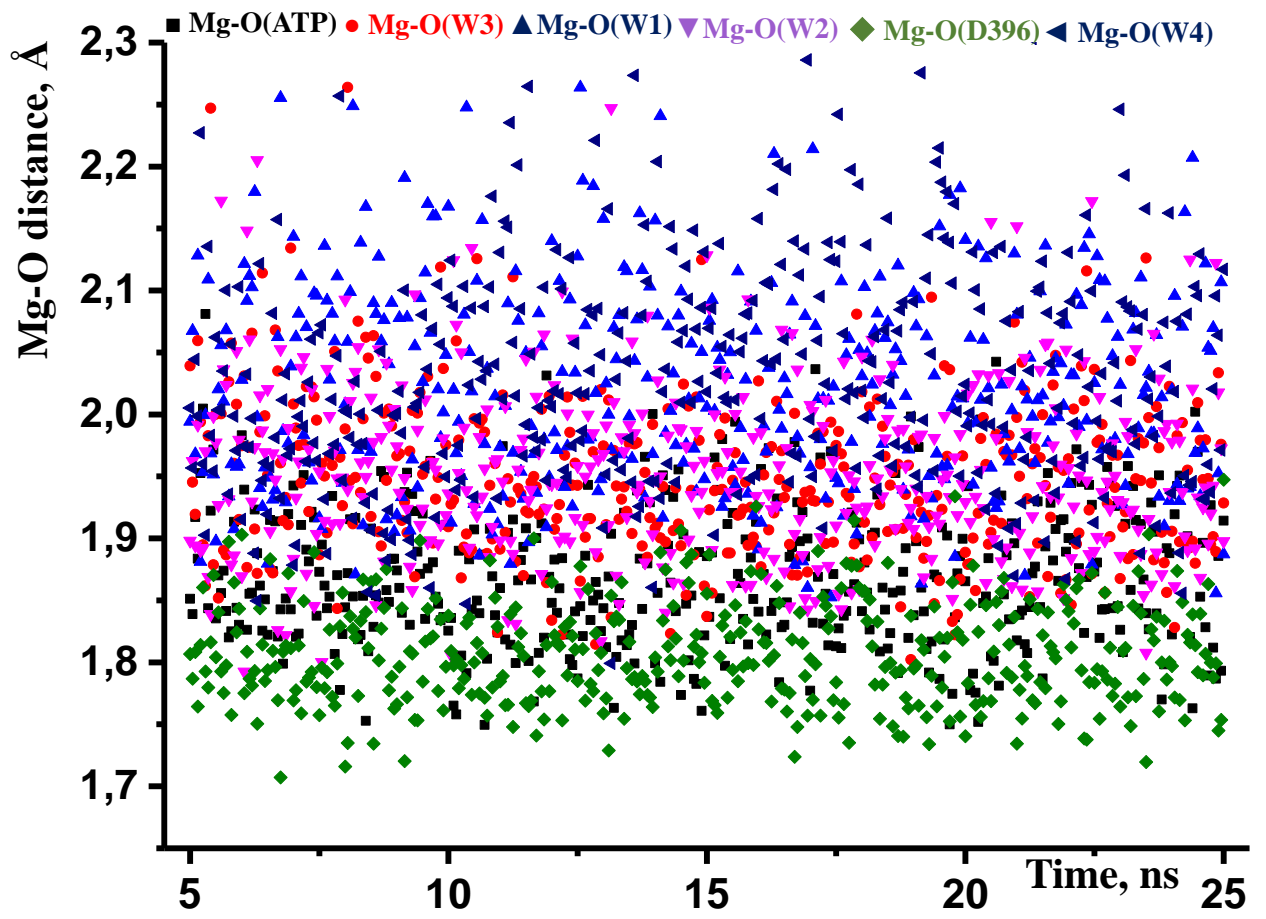

Figure S4. Plot of $\mathrm{Mg}-\mathrm{O}$ distances in the $\mathrm{ES}_{\mathrm{A}}$ structure. 